\title{
Temporal analysis of electroretinographic responses in fishes with rod-dominated and mixed rod-cone retina
}

\author{
Milena Miloševićn Željka Višnjić-Jeftić $^{2}$, Ilija Damjanović ${ }^{3}$ Miroslav Nikčević ${ }^{2}$ Pavle Andjus ${ }^{1}$ \\ and Zoran Gačić ${ }^{2}$ \\ ${ }^{1}$ School of Biology University of Belgrade, Studentski trg 3, 11001 Belgrade, Serbia \\ ${ }^{2}$ Institute for Multidisciplinary Research, University of Belgrade, Kneza Višeslava 1, 11000 Belgrade, Serbia \\ ${ }^{3}$ Institute for Problems of Information Transmision, Russian Academy of Science, Ermolova 19, 101447 Moscow, Russia
}

\begin{abstract}
Photoreceptor content of fish retinas could be accessed by comparative electroretinographic (ERG) studies using flickering light stimuli that could separate rod-mediated vision where critical flicker frequency (CFF, frequency when the eye loses its ability to resolve individual light pulses) is usually less than $15 \mathrm{~Hz}$ from cone-mediated vision. Four fish species inhabiting different photic environments (small-spotted dogfish shark - Scyliorhinus canicula, eel - Anguilla anguilla, painted comber - Serranus scriba, Prussian carp - Carassius gibelio) were investigated. Dogfish shark $b$-wave amplitudes significantly decreased at low frequency of stimulation and CFF was reached at $3.2 \mathrm{~Hz}$. A similar effect on the $b$-wave amplitude was observed in the eel, but CFF occurred at around $20 \mathrm{~Hz}$. Conversely, $b$-waves of painted comber and Prussian carp remained unaltered under intermittent low-frequency stimulation, and CFFs were around 25 and $30 \mathrm{~Hz}$, respectively. Additional support in accessing the receptor content of fish retinas was given by the characterization of the OFF-response ( $d$-wave) after light adaptation. Monotonous time course of the $b$-wave dark adaptation indicated a rod dominated retina of the dogfish shark.

Observed results indicate that the dogfish shark possesses preponderantly rod retina, that of the eel is rod-dominated, while Prussian carp and painted comber have cone-rich retinae.
\end{abstract}

Key words: Critical flicker frequency - Dogfish shark - Eel - Painted comber - Prussian carp

\section{Introduction}

Photic conditions in the aquatic environment provide a great diversity varying in turbidity, colour, and brightness. Underwater photic condition could be divided into i) clear deep waters with scotopic (low-light) intensities that are relatively monochromatic, ii) moderately deep costal waters in both seas and lakes with maximal transmition in green, and iii) surface waters with fully available daylight spectral range (Bowmaker 1995).

Most of fishes possess a duplex retina that allows them to sense changes in spatial and temporal patterns of light (from approximately $300 \mathrm{~nm}$ in the ultraviolet to approximately $1100 \mathrm{~nm}$ in the infra-red) over an enormous range of inten-

Correspondence to: Milena Milošević, School of Biology University of Belgrade, Studentski trg 3, 11001 Belgrade, Serbia

E-mail: milmi@bio.bg.ac.rs sities (Bowmaker 1995). Rod signals mediate low-intensity (scotopic) vision, whereas the cone system subserves the upper (photopic) range of intensities. In order to show retinal photoreceptor content in fish inhabiting photic environments from moderately deep sea with photopic light level covering a broader spectrum with maximum transmission in the green (small-spotted dogfish shark) and surface waters where the full spectral range of daylight is available (eel, painted comber and Prussian carp) comparative electroretinographic (ERG) studies were performed using flickering light stimuli. In response to sufficiently long duration of photo stimuli (usually more then $1 \mathrm{~s}$ ), the ERG record consists of $a$-, $b$-, $c$ - and $d$-waves. In addition to the $a$-wave of photoreceptor origin, the $b$-, $c$ - and $d$-waves are of extrareceptor origin (ON bipolar cells and Müller glial cells, pigment epithelium, and OFF bipolar cells, respectively) (Rodieck 1973; Newman and Odette 1984; Stockton and Slaughter 1989; Shiells and Falk 1999). The increase in frequency of intermittent light 
flashes causes the decrease in the amplitudes of the $b$-waves until the critical flicker frequency (CFF) is reached. In this manner, because of different $\mathrm{rod} /$ cone temporal resolution, rod-mediated vision (CFF usually less than $15 \mathrm{~Hz}$ ) could be separated from cone-mediated vision (Dodt 1951; Conner and MacLeod 1977).

The small-spotted dogfish shark is a one of the most abundant elasmobranch fishes in the south Adriatic (Andjus et al. 1998) and is easily kept in captivity, in cold-water recirculation systems. The dogfish shark is a rhodopsin possessing marine species with a rod dominated retina containing a single layer of photoreceptors indicated electrophysiologically by Dowling and Ripps (1970, 1971), and hystologically by Bozzano et al. (2001), and with a rodcone ratio estimated to be $>100: 1$ by Ashmore and Falk (1980). However, some authors have also seen cones in shark retinas (Stell 1972). One of the minor components of ERG, the OFF-response, appears at the end of a test flash in dogfish shark (in dark-adapted preparations as a negative deflection whereas in light adapted preparations as a positive deflection). Positive OFF-response ( $d$-wave) disappears after dark adaptation, and reappears upon repeated light adaptation (Andjus et al. 1998; Gacic et al. 2005). If it is accepted that the $d$-wave represent mainly, if not exclusively, cone functions (Andjus 2001; Ren and Li 2004), positive $d$-wave recorded in photopic conditions could indicate that cone units might exist in the retina of small-spotted dogfish shark.

Similar reaction at the end of the prolonged light stimulation (stimulus $>1 \mathrm{~s}$ ) was obtained in the eel and Prussian carp: a dark-adapted preparation was with a negative $d$-wave whereas in light adapted preparation $d$-wave changed the sign to positive (Gačić et al. 2007). The eel possesses a roddominated retina (Munz and McFarland 1977; Gordon et al. 1978; Pankhurst 1982) but Prussian carp owns at least 4 types of cone receptors (Bowmaker 1995). Of all the fishes examined in the present study, only painted comber possesses $d$-wave always positive in sign (dark- or light-adapted). It should be emphasized that the duration of light stimulation was not a limiting factor for painted comber (a predator from shallow waters with cone-reach retina), because positive $d$-wave appears even with light stimuli as short as $200 \mathrm{~ms}$ (Gačić et al. 2007).

Thus, in the present study the receptor retinal content in four fish species was accessed exclusively by electrophysiology - comparing CFF data for the $b$-wave with additional comparison to the previous data on the $d$-wave (Gačić et al. 2007). Observed electrophysiological data for the dogfish shark are consistent with histological findings of Bozzano et al. (2001), and additional insight into time course of the $b$-wave dark adaptation goes in favour of the statement that dogfish shark possesses preponderantly rod retina. Frequency dependence of $b$-wave decrease and
CFFs also indicate that the eel retina is rod-dominated, while Prussian carp and painted comber have cone-rich retinae.

\section{Materials and Methods}

\section{Animals}

Small-spotted dogfish sharks (150-250 g body mass) were caught by trawler nets in the south Adriatic, at a depth of about $100 \mathrm{~m}$. At least one month prior to experiments they were maintained in a sea-water recirculation system for experimental aquaculture, located in a dark and temperature controlled room, at $15^{\circ} \mathrm{C}$ (Kotor Institute for Marine Biology, Montenegro). Care was taken not to expose the dogfish shark long to light, as this is known to be damaging to the elasmobranch photoreceptors (Hamasaki et al. 1967).

European eels of the yellow form were electrofished during summer months in coastal running waters along the Kotor Bay (Montenegro). Upon capture the fish was kept for at least 20 days prior to experiments, in a fresh-water (natural habitat of this form; Deelder 1984) aquarium, located in the same dark and temperature-controlled room $\left(15^{\circ} \mathrm{C}\right)$ as the sea-water aquaculture system with dogfish shark.

Painted combers were caught by net in south Adriatic and kept for a month prior to experiment in a sea-water aquarium in the dark and temperature-controlled room $\left(15^{\circ} \mathrm{C}\right)$.

Prussian carp was electrofished in the floodplain zone of the Danube river $(1136 \mathrm{~km})$. Fishes were kept in captivity for at least 15 days in order to acclimatize to experimental conditions (12: 12 light/dark regime due to the particularly seisitive cyrcadian clock of this species (Bassi and Powers 1987; Iigo et al. 1997; Ribelayga et al. 2002, 2004) in a temperature-controlled room at $15^{\circ} \mathrm{C}$ ) in a fresh-water recirculation system for experimental aquaculture (Institute for Multidisciplinary Research, University of Belgrade, Serbia).

All animal use was approved by the Ethical Council of Faculty of Biology, University of Belgrade.

\section{Isolated eyecup preparation}

Due to technical difficulties (related to fish length) the eyecup preparation of the dogfish shark could not be maintained in situ (as seen below). Nevertheless, it has been previously shown that the isolated preparation bares similar ERG characteristics as the in situ preparation (Andjus et al. 1998). Isolated eyecups were prepared under dim red light, from dogfish shark eyeballs (about $10 \mathrm{~mm}$ in diameter) excised after rapid decapitation. The preparations were surgically deprived of cornea, lens and most of the vitreous. The eyecup was filled with elasmobranch Ringer (Rybak 1973) and 
placed on a cotton-wool bed soaked with the same solution, in a plastic temperature-controlled chamber inside a lightproof Faraday cage. After mounting, the preparations were dark-adapted for additional $30 \mathrm{~min}$ before actual ERG recording. In the case of photopic $b$-wave recording, the eyecup was continuously exposed to a $500 \mathrm{~nm}$ background illumination capable, at its onset, to evoke a $b$-wave response of saturating amplitude and to reduce sensitivity more than 3000-fold.

\section{In situ eyecup preparation}

Eel, Prussian carp and painted comber were anesthetized (phenobarbital sodium) and curarized (tubocurarine) following procedures recommended by Hamasaki et al. (1967) adjusting the dosage so as to induce the arrest of respiratory movements. Artificial respiration was provided continuously by forcing aerated and temperature-controlled water through the gills. The immobilized fish were positioned laterally on a plastic platform inside a light-proof Faraday cage. The in situ eyecup was prepared in the same way as in the case of isolated preparations of the dogfish shark (removal of cornea, lens and most of the vitreous), and it was filled with teleosts Ringer.

\section{Recordings and stimulation}

ERG potentials were detected with non-polarizable chlorided silver electrodes (Ag-AgCl, model EP2 (World Precision Instruments, Inc.)). The active electrode was introduced in the interior of the saline filled eyecup while the reference electrode was in contact with the cotton-wool bed underneath the isolated preparations of the dogfish shark, or in the retro-orbital space behind the in situ eyecup in other experimental species. Electrodes were connected to the input stage of a directly coupled differential preamplifier, and responses were recorded by means of a Polaroid camera from a storage oscilloscope display (dogfish shark, eel and painted comber) or transferring from a preamplifier to a computer (Prussian carp) by means of an $\mathrm{AD}$-converter PCI-20428W-1 (8-bit; 125 Hz sampling rate). Photic stimuli were delivered by a single-beam optical system using an $8 \mathrm{~V}-50 \mathrm{~W}$ tungsten-halogen lamp as the light source $(282$ $\mu \mathrm{W} / \mathrm{cm}^{2}$ - maximum achievable intensity), providing independent control of intensity (neutral density filters), duration and frequency (electromagnetic shutter, UniBlitz model T132), and spectral composition (interference filters) of the test flashes. Light intensities were calibrated and checked by placing the active surface of the custom-made radiometer probe in the position usually occupied by the eyecup preparation.

A possibility of retinomotor movements was excluded in these experiments.

\section{CFF estimation}

CFF measured via the ERG is dependent on a variety of factors, namely adaptation state, background intensity, stimulus intensity, and the subtended visual angle of the source. In this study, all factors were equal for all the species: they were all completely dark-adapted before being presented with a flickering light stimulus, without background light, and the eye was always bathed with a circle of light that was larger than the eye itself. To ensure that the same parameter was measured for all species, the maximum CFF, which is the highest flicker rate that the eye is capable of following at any intensity, was used.

\section{Results and Discussion}

Dogfish shark eyes were exposed to intermittent light stimuli of different frequency and duration. Series of ERGs obtained with flashing light stimuli (Fig. 1a, right - frequency of light flashes increasing from bottom to top) show ragged trace mainly originating from $b$-wave, that gradually reduces with increasing stimulation frequency and completely disappears at $3.2 \mathrm{~Hz}$, leaving behind a smooth, non-ragged trace, typical for the $c$-wave obtained with a prolonged stimulus of constant intensity (Gačić et al. 2007). Dependence of the amplitude of the ragged trace (expressed as a percent of initial value) on the logarithm of stimulation frequency is presented in Fig. 1a, left. It is obvious that CFF was reached around 3.2 stimuli per second. The influence of the duration of intermittent stimuli (light intervals from 31-750 ms) of constant frequency $(1 \mathrm{~Hz})$ on temporal resolution of the $b$-waves is shown in Fig. 1b. It was necessary to increase the duration of the light interval to $750 \mathrm{~ms}$ (250 ms dark interval at $1 \mathrm{~Hz}$ stimulation) to practically reach the CFF. The $c$-wave was linearly increasing in amplitude with the logarithm of duration of intermittent stimulation (Fig. 1b). Relationship between dark and light intervals at intermittent stimulation (Fig. 1c) shows that with prolonged light via dark interval (constant frequency of stimulation, $1 \mathrm{~Hz}$ ), CFF curve shifts to higher intensities (i.e. longer light phase of intermittent stimuli). The end of stimulation was characterized by a small positive $d$-wave (Fig. 1b, right - except with $31 \mathrm{~ms}$ illumination, see bottom trace), as a consequence of partial light adaptation during the intermittent stimulation (see below).

Similar effect was observed in eel where $b$-wave amplitude significantly decreased already at low frequency of stimulation (Fig. 2). On the other hand, in painted comber, $b$-waves of intermittent ERGs did not change their amplitudes at low frequencies. They started to decay at stimulus frequencies higher than $2 \mathrm{~Hz}$ and CFF occurred at a frequency of around 


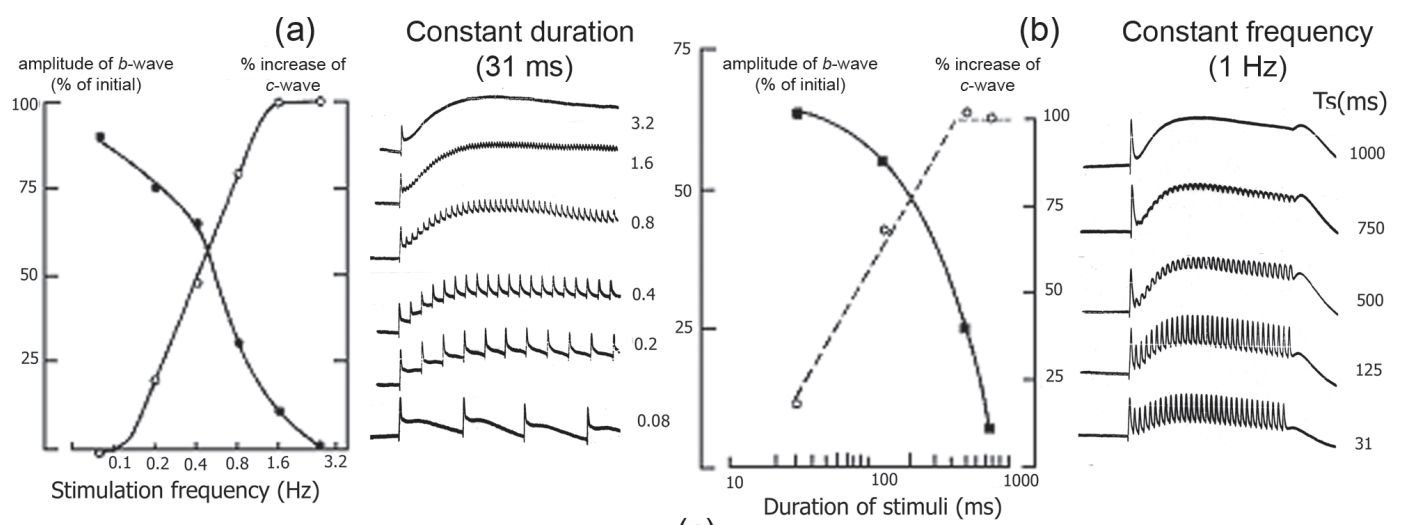

(c)

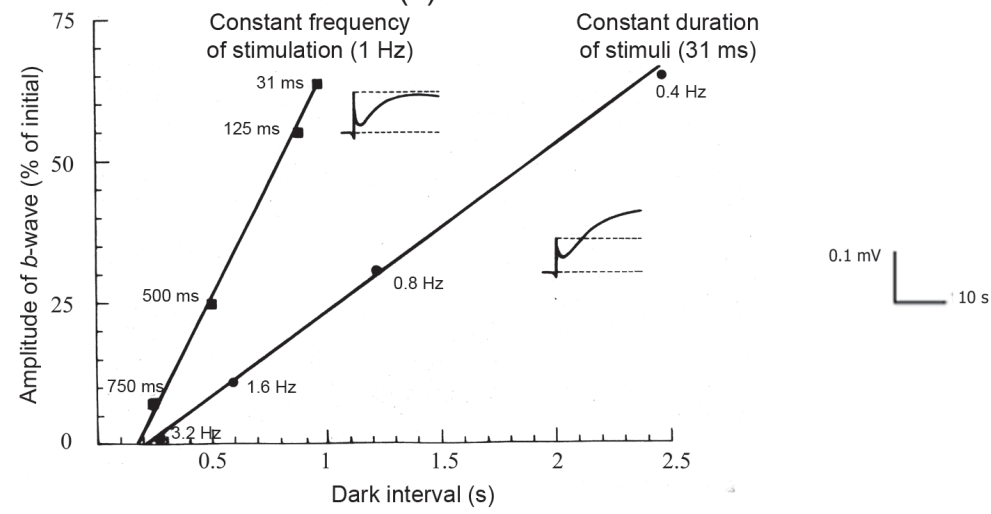

Figure 1. Responsiveness to intermittent stimulation in dogfish shark. a) Right: responses of dogfish shark retina to intermittent stimuli (31 ms) at different frequencies (indicated by each traces). Left: dependence of the $b$ - and $c$-wave amplitudes on the stimulation frequency (amplitudes expressed as percentage of maximal value, $n=5)$. b) Right: responses of dogfish shark retina to constant frequency intermittent stimuli $(1 \mathrm{~Hz})$ of different duration (indicated by corresponding traces). Left: dependence of the $b$-wave and $c$-wave amplitudes on the duration of stimuli (amplitudes expressed as a percentage of maximal value, $n=5)$. c) Dependence of $b$-wave amplitudes on dark interval $(n=5)$. Amplitude of $b$-wave is expressed as percentage of initial value. Insets by each line represent original ERG recordings for the cases of CFF. Calibration bars: $0.1 \mathrm{mV}, 10 \mathrm{~s}$.

$25 \mathrm{~Hz}$. The rate of $b$-wave decay with frequency was much lower than in eel (Fig. 2).

Results obtained in eel and painted comber showed that these species possess different kinds of retina, in eel rod-dominated and in painted comber cone-dominated retina (Munz and McFarland 1977; Gordon et al. 1978; Pankhurst 1982). Different photoreceptor contents could be explained by environmental conditions. Namely, in a nocturnal animal, such as the eel, photopic (color) vision is not necessary. On the other hand, painted comber is a predator species from highly illuminated shallow waters (diurnal fish) with well developed color vision (twin cones, Gacic et al. 2005). It is interesting that Gordon et al. (1978) concluded on the basis of spectral sensitivity investigation, that the eel retina possesses two photopic pigments, in spite of many anatomical and electrophysiological studies (Carliste and Denton 1959; Bridges 1972; Beatty 1975) that suggested rod-dominated retina in the eel (with presence of long single cones).

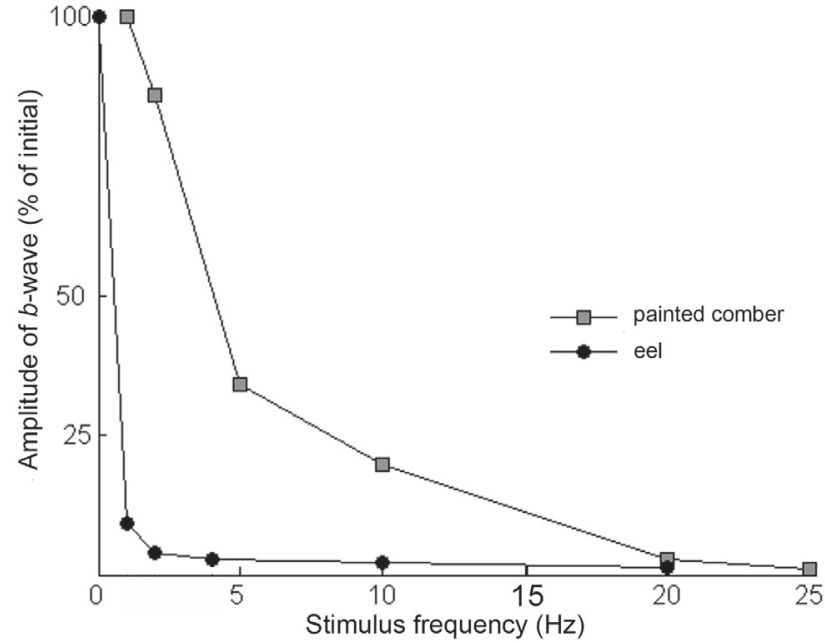

Figure 2. Comparison of subsequent $b$-wave amplitude dependence on stimulus frequency of eel $(n=8)$ and painted comber $(n=4)$. Amplitude of $b$-wave is expressed as percentage of initial value. 
(a)

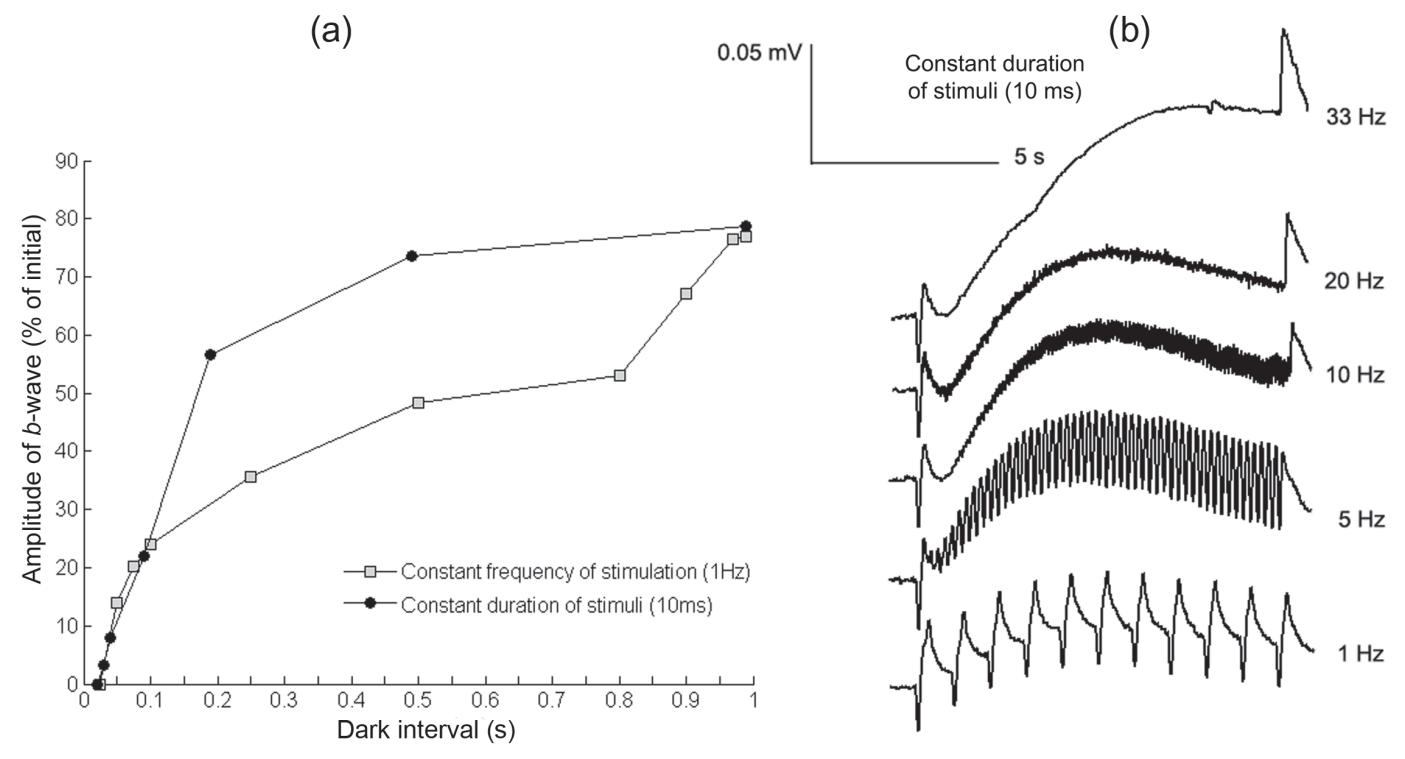

Figure 3. Responsiveness to intermittent light stimulation in the Prussian carp. a) Dependence of $b$-wave amplitudes on dark interval $(n=4)$. Amplitude of $b$-wave is expressed as percentage of initial value. b) Responses of Prussian carp retina to intermittent stimuli $(10 \mathrm{~ms})$ at different frequencies (indicated by corresponding traces, $n=4)$. Calibration bars: $0.05 \mathrm{mV}, 5 \mathrm{~s}$.

ERG responses to intermittent light stimulation of Prussian carp eyes and CFF curves are shown in Fig. 3. While in dogfish shark, the amplitude of $b$-waves shows linear decrease with decrease of dark interval (Fig. 1c), Prussian carp shows rather different temporal properties. Both curves are break-pointed. With constant duration of stimuli $(10 \mathrm{~ms}$; specific for Prussian carp; Mora-Ferrer and Behrend 2004) a change in temporal properties occurs at $5 \mathrm{~Hz}$ frequency of stimulation, whereas increasing duration of stimuli with constant frequency of $1 \mathrm{~Hz}$ modifies the dynamics of reaction at around $0.8 \mathrm{~s}$ of dark interval (200 ms light phase) from rod- to cone-like response (Fig. 3a). Series of ERGs obtained with constant duration of stimuli $(10 \mathrm{~ms})$ with increasing frequency of stimulation (Fig. 3b) show that the OFF-response ( $d$-wave) occurs at around 5 stimuli per second (although it ressembles the form of the response at $1 \mathrm{~Hz}$ it is clearly a different ERG wave as compared to preceding responses to intermittent stimulation), and enlarges its amplitude as the frequency of stimulation increases (higher light intensities that are detected by cone system).

An indication of rod-cone break that occurs around $5 \mathrm{~Hz}$ (0.2 s dark interval in Fig. 3 ) and appearance of positive $d$-wave at the same frequency is the halmark of a well-developed functioning cone system in Prussian carp (Andjus 2001; Ren and Li 2004).

Temporal resolution in investigated fishes is summarized in Fig. 4, where response amplitudes scaled to their maxima (which yields the gain) are plotted $v s$. stimulus frequency on a double logarithmic scale. In dogfish shark

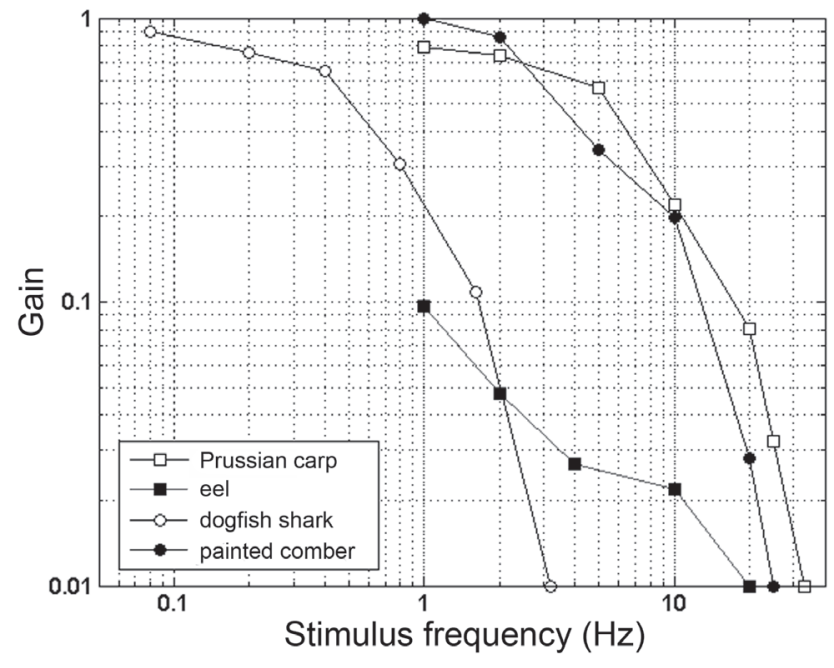

Figure 4. Gain plot for four studied fish species. Response amplitude normalized to its maximum which yields the gain, plotted $v s$. the stimulus frequency on a double logarithmic scale.

$b$-wave amplitude significantly decreased at low frequency of stimulation and CFF was reached at $3.2 \mathrm{~Hz}$. Similar effect on the $b$-wave amplitude was observed in the eel, but CFF was reached at around $20 \mathrm{~Hz}$. In fishes with well developed color vision, painted comber and Prussian carp, CFF occurred at a frequency of around $25 \mathrm{~Hz}$ and around $33 \mathrm{~Hz}$, respectively. 


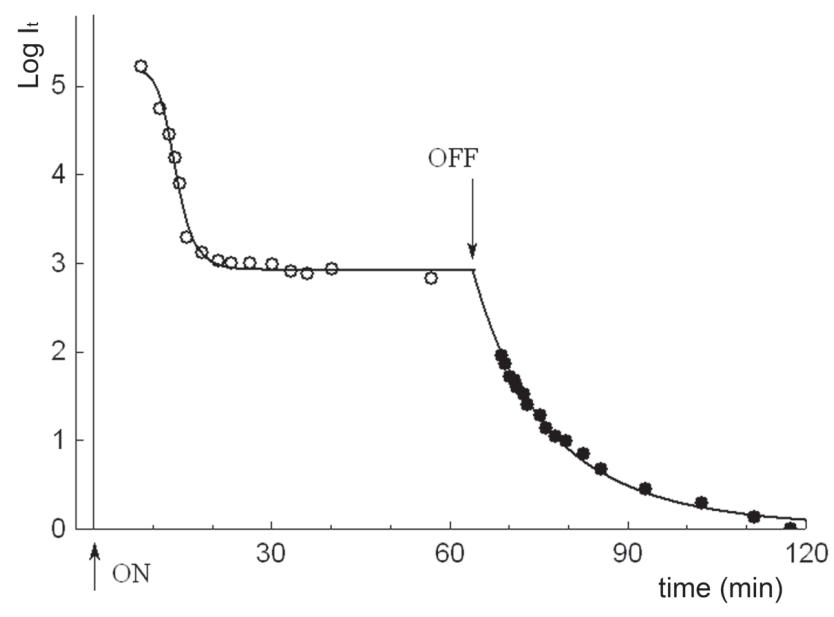

Figure 5. Light adaptation of the S. canicula eyecup $(n=5)$. Time course of the logarithm value of the $b$-wave threshold $\left(\mathrm{I}_{\mathrm{t}}\right)$ during background illumination (open circles after $\mathrm{ON}$ arrow) and during dark readaptation (closed circles after OFF arrow). Fitting according to equation: $y=a+b /\left(1+(x / c)^{d}\right)$. In photopic condition parameter values were $a=2.923, b=2.257, c=13.855$, $d=8.727$ while in scotopic were $a=-0.011, b=203.562, c=$ 28.358, $d=5.207$.

The positive $d$-wave in small spotted dogfish shark (Fig. 1b, right) is the electrophysiological indication of cone units in the retina and this was also tested by performing experiments with light adaptation. As it is shown in Fig. 5, it is possible to follow the process of light adaptation by recording the $b$-wave from the dogfish shark eyecup. Eyecup was first exposed to constant bright light stimuli (ON arrow) and after that to the dark (OFF arrow). At the beginning of stimulation with the bright light (bright background illumination), threshold to the short light stimuli $(200 \mathrm{~ms})$ rose to infinity (there was no ERG response even with maximal light intensity stimulus applied). After a few minutes of recovery the threshold stimuli dropped down to a new level (photopic condition). After the end of background illumination (Fig. 5, OFF arrow) and after approximately two hours the final value characteristic for the scotopic condition ( 0 on the ordinate) is reached. Monotonous dark adaptation following a period of background illumination indicates the absence of any "kink" which would be caused by differences in cone and rod adaptation time course.

The observed electrophysiological data on CFF thus indicate that the dogfish shark possess predominantly rod retina, that of the eel is rod-dominated, while Prussian carp and painted comber have cone-rich retinae. These data are congruent with the previously published $d$-wave characterization except in the case of dogfish shark (Gačić et al. 2007). The latter discrepancy could be explained by an only indirect access to receptor content by $d$-wave analysis.

Acknowledgement. Supported by grants No. 143045 and 143054 of the Serbian Ministry of Science.

\section{References}

Andjus R. K., Konjević Dj., Damjanović I., Gačić Z., Andjus P. R. (1998): Dogfish sharks and eels as experimental models. II. Electroretinography: effects of temperature and light. Iugosl. Physiol. Pharmacol. Acta 34, 381-399

Andjus R. K. (2001): General Physiology and Biophysics: modulus 6 and 7: sensitive receptors. Center for Multidisciplinary Studies, University of Belgrade, School of Biology, University of Belgrade (in Serbian)

Ashmore J. F., Falk G. (1980): Responses of rod-bipolar cells in dark-adapted retina of the dogfish, Scyliorhinus canicula. J. Physiol. 300, 115-150

Bassi C. J., Powers M. K. (1987): Circadian rhythm in goldfish visual sensitivity. Invest. Ophthalmol. Vis. Sci. 28, $1811-1815$

Beatty D. D. (1975): Visual pigments of the American eel Anguilla rostrata. Vision Res. 15, 771-776; doi:10.1016/00426989(75) $90254-0$

Bowmaker J. K. (1995): The visual pigments of fishes. Prog. Retin. Eye Res. 15, 1-31; doi:10.1016/1350-9462(95)00001-1

Bozzano A., Murgia R., Vallerga S., Hirano J., Archer S. (2001): The photoreceptor system in the retina of two dogfishes, Scyliorhinus canicula and Galeus melastomus: possible relationship with depth distribution and predatory lifestyle. J. Fish Biol. 59, 1258-1278; doi:10.1111/j.10958649.2001.tb00190.x

Bridges C. D. B. (1972): The rhodopsin-porphyropsin visual system. In: Handbook of Sensory Physiology. (Ed. H. J. A. Dartnall), Vol. 7, pp. 417-480, Springer, New York

Carlisle D. B., Denton E. J. (1959): On the metamorphosis of the visual pigments of Anguilla anguilla (L.). J. Mar. Biol. Ass. U. K. 38, 97-102; doi:10.1017/S0025315400015629

Conner J. D., MacLeod D. I. (1977): Rod photoreceptors detect rapid flicker. Science 195, 698-699; doi:10.1126/ science. 841308

Deelder C. L. (1984): Synopsis of Biological Data on the Eel, Anguilla anguilla. (Linnaeus, 1758). Food and Agriculture Organization Fisheries Synopsis (No. 80, Rev. 1) p. 73

Dodt E. (1951): Cone electroretinography by flicker. Nature 168, 738-740; doi:10.1038/168738a0

Dowling J. E., Ripps H. (1970): Visual adaptation in the retina of skate. J. Gen. Physiol. 56, 491-520; doi:10.1085/ jgp.56.4.491

Dowling J. E., Ripps H. (1971): S-potentials in the skate retina: intracellular recordings during light and dark adaptation. J. Gen. Physiol. 58, 163-189; doi:10.1085/jgp.58.2.163

Gacic Z., Damjanovic I., Konjevic Dj., Bajic A., Milosevic M., Andjus P. R., Mickovic B., Andjus R. K. (2005): Influence of phototopic environment on the form of the fish 
electroretinographic off-response. Ann. N. Y. Acad. Sci. 1048, 437-440; doi:10.1196/annals.1342.058

Gačić Z., Damjanović I., Bajić A., Milošević M., Mićković B., Nikčević M., Andjus P. R. (2007): The d-wave in fish and the state of light adaptation. Gen. Physiol. Biophys. 26, 260-267

Gordon J., Shapley R. M., Kaplan E. (1978): The eel retina (receptor classes and spectral mechanisms). J. Gen. Physiol. 71, 123-138; doi:10.1085/jgp.71.2.123

Hamasaki D. I., Bridges C. D. B., Meneghini K. A. (1967): The electroretinogram of three species of elasmobranchs. In: Sharks, Skates, and Rays. (Eds. P. W. Gilbert, R. F. Mathewson and D. P. Rall). Johns Hopkins Press, Baltimore

Iigo M., Hara M., Ohtani-Kaneko R., Hirata K., Tabata M., Aida K. (1997): Photic and circadian regulations of melatonin rhythms in fishes. Biol. Signals 6, 225-232; doi:10.1159/ 000109132

Mora-Ferrer C., Behrend K. (2004): Dopaminergic modulation of photopic temporal transfer properties in goldfish retina investigated with the ERG. Vision Res. 44, 2067-2081; doi:10.1016/j.visres.2003.11.028

Munz F., McFarland W. N. (1977): Evolutionary adaptations of fishes to the photopic environment. In: Handbook of Sensory Physiology. (Ed. F. Crescitelli), Vol. 7, pp. 193-274, Springer-Verlag, Berlin

Newman E. A., Odette L. L. (1984): Model of electroretinogram b-wave generation: a test of the $\mathrm{K}^{+}$hypothesis. J. Neurophysiol. 51, 164-182

Pankhurst N. W. (1982): Relation of visual changes to the onset of sexual maturation in the European eel Anguilla anguilla (L.). J. Fish Biol. 21, 127-140; doi:10.1111/j.10958649.1982.tb03994.x
Ren J., Li L. (2004): A circadian clock regulates the process of ERG b- and d-wave dominance transition in dark-adapted zebrafish. Vision Res. 44, 2147-2152; doi:10.1016/ j.visres.2004.03.022

Ribelayga C., Wang Y., Mangel S. C. (2002): Dopamine mediates circadian clock regulation of rod and cone input to fish retinal horizontal cells. J. Physiol. 544, 801-816; doi:10.1113/jphysiol.2002.023671;

Ribelayga C., Wang Y., Mangel S. C. (2004): A circadian clock in the fish retina regulates dopamine release via activation of melatonin receptors. J. Physiol. 554, 467-482; doi:10.1113/jphysiol.2003.053710

Rodieck R. W. (1973): The vertebrate retina, principles of structure and function. W. H. Freeman \& Co., San Francisco

Rybak B. (1973): Explorations circulatoires. Gauthier-Villars, Paris

Shiells R. A., Falk G. (1999): Contribution of rod, on-bipolar, and horizontal cell light responses to the ERG of dogfish retina. Vis. Neurosci. 16, 503-511; doi:10.1017/ S0952523899163119;

Stell W. R. (1972): The structure and morphologic relations of rods and cones in the retina of the spiny dogfish, Squalus. Comp. Biochem. Physiol. 42, 141-151; doi:10.1016/03009629(72)90374-X

Stockton R. A., Slaughter M. M. (1989): B-wave of the electroretinogram. A reflection of ON bipolar cell activity. J. Gen. Physiol. 93, 101-122; doi:10.1085/jgp.93.1.101

Received: August 5, 2008

Final version accepted: December 11, 2008 